\title{
Erratum to: Careers and wages in the Dutch East India Company
}

\section{Claudia Rei}

Published online: 24 August 2013

(C) Springer-Verlag Berlin Heidelberg 2013

\section{Erratum to: Cliometrica \\ DOI 10.1007/s11698-013-0093-3}

In the original publication of the article, Tables 5, 7 and 8 were published incorrectly as provided by the author. The correct tables should read as below;

The online version of the original article can be found under doi:10.1007/s11698-013-0093-3.

C. Rei $(\bowtie)$

Department of Economics, Vanderbilt University, Nashville, TN, United States

e-mail: claudia.rei@vanderbilt.edu 
Table 5 Explaining career length

\begin{tabular}{|c|c|c|c|c|c|c|c|}
\hline & (1) & (2) & (3) & (4) & (5) & (6) & (7) \\
\hline Civil & $\begin{array}{l}-6.87 * * * \\
(2.57)\end{array}$ & & & & & & \\
\hline Maritime & & $\begin{array}{l}5.82 * \\
(3.05)\end{array}$ & & $\begin{array}{l}7.02 * * \\
(3.07)\end{array}$ & $\begin{array}{l}6.87 * * \\
(3.00)\end{array}$ & $\begin{array}{l}9.80 * * * \\
(2.31)\end{array}$ & $\begin{array}{l}9.73 * * * \\
(2.31)\end{array}$ \\
\hline Military & & & $\begin{array}{l}5.25 \\
(3.99)\end{array}$ & $\begin{array}{l}7.20 * \\
(3.97)\end{array}$ & $\begin{array}{l}7.20 * \\
(3.87)\end{array}$ & $\begin{array}{l}10.12 \text { *** } \\
(1.89)\end{array}$ & $\begin{array}{l}10.12 * * * \\
(2.93)\end{array}$ \\
\hline Entry age & $\begin{array}{l}-.39 * \\
(.22)\end{array}$ & $\begin{array}{l}-.50 * * \\
(.21)\end{array}$ & $\begin{array}{l}-.52 * * \\
(.22)\end{array}$ & $\begin{array}{l}-.40 * \\
(.22)\end{array}$ & $\begin{array}{l}-.40^{*} \\
(.21)\end{array}$ & & \\
\hline Death & $\begin{array}{l}.96 \\
(2.32)\end{array}$ & $\begin{array}{l}.89 \\
(2.37)\end{array}$ & $\begin{array}{l}.87 \\
(2.40)\end{array}$ & $\begin{array}{l}1.22 \\
(2.34)\end{array}$ & & $\begin{array}{l}.08 \\
(1.86)\end{array}$ & \\
\hline Dutch & $\begin{array}{l}-1.72 \\
(4.73)\end{array}$ & $\begin{array}{l}-2.37 \\
(4.86)\end{array}$ & $\begin{array}{l}-.71 \\
(4.94)\end{array}$ & $\begin{array}{l}-1.45 \\
(4.81)\end{array}$ & & & $\begin{array}{l}.44 \\
(2.97)\end{array}$ \\
\hline _Cons & $\begin{array}{l}37.12 * * * \\
(7.03)\end{array}$ & $\begin{array}{l}31.52 * * * \\
(7.28)\end{array}$ & $\begin{array}{l}34.05^{* * *} \\
(7.56)\end{array}$ & $\begin{array}{l}30.39 * * * \\
(7.52)\end{array}$ & $\begin{array}{l}29.58^{* * * *} \\
(4.99)\end{array}$ & $\begin{array}{l}18.94 * * * \\
(1.46)\end{array}$ & $\begin{array}{l}18.65 * * * \\
(2.92)\end{array}$ \\
\hline$N$ & 76 & 76 & 76 & 76 & 77 & 115 & 114 \\
\hline$R^{2}$ & .1753 & .1382 & .1155 & .1768 & .1783 & .1887 & .1865 \\
\hline
\end{tabular}

Dependent variable: career length; significance: $* 10 \%, * * 5 \%, * * * 1 \%$

Table 7 Waiting time for promotion in the civil sector

\begin{tabular}{llllrr}
\hline From-to & Promotions & Mean & SD & Min & Max \\
\hline $1-2$ & 25 & 5.6 & 3.7 & 0 & 18 \\
$1-3 *$ & 26 & 4.5 & 2.8 & 0 & 10 \\
$2-3$ & 24 & 4.3 & 2.5 & 0 & 9 \\
$3-4$ & 62 & 8.6 & 4.8 & -13 & 17 \\
$4-5$ & 32 & 5.7 & 3.9 & 0 & 15 \\
$5-6$ & 16 & 5.4 & 2.6 & 1 & 10 \\
\hline
\end{tabular}

* Direct promotion, not through level 2 
Table 8 Fast tracks in promotions

\begin{tabular}{lrrrrr}
\hline & Entry-1 & Entry-2 & Entry-3 & Entry-4 & Entry-5 \\
\hline $1-2$ & -.3204 & & & \\
$1-3$ & .1083 & & & \\
$1-4$ & .3345 & & & \\
$1-5$ & .1815 & & & \\
$1-6$ & .4633 & & & \\
$2-3$ & & .1023 & & \\
$2-4$ & .6049 & & & \\
$2-5$ & .5607 & & & \\
$2-6$ & .9397 & & & \\
$3-4$ & & & -.2385 & \\
$3-5$ & & -.1942 & & \\
$3-6$ & & -.0346 & & \\
$4-5$ & & & & \\
$4-6$ & & & & & \\
$5-6$ & & & & & \\
\hline
\end{tabular}

